\section{RSP}

http://www.rsp.fsp.usp.br/
Revista de Saúde Pública

\title{
Individual and contextual factors associated to the self-perception of oral health in Brazilian adults
}

\author{
Janmille Valdivino da Silva', Angelo Giuseppe Roncalli da Costa Oliveira" \\ I Universidade Federal do Rio Grande do Norte. Faculdade de Odontologia. Programa de Pós-Graduação em \\ Saúde Coletiva. Natal, RN, Brasil \\ " Universidade Federal do Rio Grande do Norte. Faculdade de Odontologia. Departamento de Saúde Coletiva. \\ Natal, RN, Brasil
}

\section{ABSTRACT}

OBJECTIVE: To analyze how individual characteristics and the social context, together, are associated with self-perception of the oral health.

METHODS: A multilevel cross-sectional study with data from the Brazilian National Health Survey 2013, the United Nations Development Program, and the National Registry of Health Establishments. The explanatory variables for the "oral health perception" outcome were grouped, according to the study framework, into biological characteristics (sex, color, age), proximal social determinants (literacy, household crowding, and socioeconomic stratification), and distal (years of schooling expectancy at age 18, GINI, Human Development Index, and per capita income). The described analysis was performed, along with bivariate Poisson analysis and multilevel Poisson analysis for the construction of the explanatory model of oral health perception. All analyzes considered the sample weights.

RESULTS: Both the biological characteristics and the proximal and distal social determinants were associated with the perception of oral health in the bivariate analysis. A higher prevalence of bad oral health was associated to lower years of schooling expectancy $(\mathrm{PR}=1.31)$, lower per capita income $(\mathrm{PR}=1.45)$, higher income concentration $(\mathrm{PR}=1.41)$, and worse human development $(\mathrm{PR}=1.45)$. Inversely, oral health services in both primary and secondary care were negatively associated with oral health perception. All the biological and individual social characteristics, except reading and writing, made up the final explanatory model along with the distal social determinants of the Human Development Index and coverage of basic care in the multilevel analysis.

CONCLUSIONS: Biological factors, individual and contextual social determinants were associate synergistically with the population's perception of oral health. It is necessary to improve individual living conditions and the implementation of public social policies to improve the oral health of the population.

DESCRIPTORS: Adult. Diagnostic Self Evaluation. Oral Health. Socioeconomic Factors. Health Surveys.

\footnotetext{
Copyright: This is an open-access article distributed under the terms of the Creative Commons Attribution License, which permits unrestricted use, distribution, and reproduction in any medium, provided that the original author and source are credited.

Janmille Valdivino da Silva

Ciência e Tecnologia do Rio

Av. José Rodrigues de Aquino Filho, 59215-000 Nova Cruz, RN, Brasi

Received: Nov 17, 2016

How to cite: Silva JV, Roncalli AG Individual and contextual factors associated to the self-perception of oral health in Brazilian adults. Rev Saude Publica. 2018;52:29.
} 


\section{INTRODUCTION}

Individual self-perception of health has been increasing its importance as a parameter for health status assessment of the population. As a measure, it can be considered a strong health predictor due to its relationship with clinical conditions and other indicators of both morbidity and mortality ${ }^{1}$.

In some countries with huge populations (as in Brazil), performing epidemiological population-based studies is usually very expensive and requires a great amount of both human and technological resources. In addition, clinical examinations are needed in some studies, increasing the resources needed and hence making them unfeasible $e^{2,3}$. The self-perception of health associated with treatment needs, as well as the degree of satisfaction with health status, have been used more frequently in health surveys.

Therefore, some population-based studies such as the National Health Research (PNS), performed between 2013 and 2014, have used the self-perception of the Brazilian population to obtain information about morbidity, risk factors, and healthy lifestyles ${ }^{4}$.

It is important to highlight the subjectivity beyond the self-assessment of health because its measure is a result of a complex web of factors, which includes individual characteristics, personal experiences, and also the environment where these subjects are living ${ }^{5,6}$. Nogueira ${ }^{7}$ indicates that the production and distribution of health is associated a relationship that man keeps with the social world. Mansuyr et al. ${ }^{5}$ observing the relationship between social environment and health in 45 countries showed an association between socioeconomic inequality and social capital with a self-perception of health, strengthening the importance of the theory of social health determination.

Regarding oral health, this context is no different. Oral health self-perception is also associated with individual factors and usually reveals an association with social factors ${ }^{8-10}$. In Brazil, the poor perception of oral health has been associated with low income and schooling, deteriorated housing conditions, inequality of income distribution, among other social factors ${ }^{6,11}$.

As a perspective to analyze the oral health conditions of populations, studies on social health determinants have been considered relevant for the identification of future strategies focused on oral health promotion. Considering that oral health promotion refers to actions on the social health determinants, aimed at favorably impacting the quality of life of individuals, according to the World Health Organization.

Despite this, nowadays, few studies ${ }^{11-14}$ have analyzed the association of both individual and contextual characteristics, together, with the oral health perception. Thus, this study aimed to analyze how individual conditions in combination with the social context where they are living are associated with the oral health perception in Brazilian adult population.

\section{METHODS}

Study of the association between a dependent variable (oral health self-perception) and several independent variables, using a multilevel regression model. Secondary data were gathered from the PNS 2013 database, the main source of our individual data. This database was linked to two others, both with aggregated data from the state (the Brazilian federation unit) level: (a) the National Census, performed by the Brazilian Institute of Geography and Statistics (IBGE) with data compiled by the Brazilian agency of the United Nations Development Program (UNDP), which has created several indicators such as the Human Development Index (HDI) among others, and (b) the National Health Facilities Register (CNES), which contains information concerning public and private health services for the whole country.

There are several models for the social health determinants. Most of them have a similar structure, usually including different levels for explaining the social determination. 
We decided on the model proposed by Dalgren and Whitehead, based on layers representing specific levels of determination. In the first level, determinants are related to individual characteristics (age, sex, and genetic factors). In a second layer, above the previous one, there are the individual lifestyle factors and another layer representing the social and community networks. In the outermost layer, there are the general socioeconomic, cultural, and environmental conditions ${ }^{15}$.

The theoretical model was built taking this model as a reference and including recent findings regarding the factors associated to oral health perception (Figure). As proximal factors, we included the variables sex and skin color and healthy eating habits, representing lifestyle factors. For the socioeconomic characteristics, the model has included classical factors related to socioeconomic status (an indicator based on possession of goods) and formal education. All these variables were gathered from the PNS 2013 (Table 1).

The PNS 2013 was a national household-based survey that aimed to characterize the health status and lifestyles of the Brazilian population, as well as aspects related to health care ${ }^{16}$. This survey was based on cluster sampling, using three stages: census tracks (Primary Sample Unity - PSU); households (Secondary Units) and an adult resident (Tertiary Unit) selected from a list made at the time of the interview. Due to this, the survey has different sample weights for the PSU, for the households, and for the selected resident. Thus, data from more than 60 thousand adults were used, which were selected for the interviews, and the analysis considered the complex sample design.

In the distal level, we included variables related to socioeconomic context plausibly associated with oral health status. Therefore, we included the average of per capita income, the Gini index, representing income inequality, and the years of schooling expectancy at 18 years old, meaning the educational context. We also included the Human Development Index (HDI), which is a combined measure of income, education, and longevity. We included the presence of oral health teams in primary care services, which means the population coverage and hence the possibility to obtain access to oral health services (Figure).

Multilevel modeling was used to assess both individual and contextual determinants. In multilevel analysis, the contextual levels can be considered as social aggregates, as they have a significant effect on their members. Therefore, individuals are usually considered as the first (lowest) level and the communities (neighborhood, cities or states, for example) where they are living are the second (upper) level ${ }^{17}$.

All variables were analyzed to verify the presence of missing data and outliers. From the PNS 2013, we extracted 64,308 records, corresponding to all the individuals interviewed, of 18 years and older. The PSN 2013 sample was representative for a Brazilian adult population aggregated at the State level. There were no missing data for age, skin color, reading and writing ability, socioeconomic stratification (Brazil Criterion ${ }^{18}$ ), healthy eating habits, and all contextual variables. Oral health perception had $6.4 \%$ of missing data and sex had only three missing cases. According to Hair Jr et al..$^{19}$, missing data below $10 \%$ can be ignored, as long as they are missed at random. The missing data were Missing Completely at Random (MCAR). As we used complete data and also considering the sample size, the significance of associations was not affected. The final model counted a sample of 60,199 individuals. At the contextual level, all data were available.

A descriptive analysis was performed, aiming to identify cut-off points or other criteria to categorize the variables. As the final variables were created, association tests such as Rao Scott chi-square test were performed between the outcome (oral health self-perception) and all independent variables, selecting those with $p$-value $\leq 0.2$, to be included in the multiple regression. Poisson regression analysis with robust variance was initially performed at an individual level to estimate the Prevalence Ratio with a respective 95\% confidence interval. A Poisson Multilevel Regression Model was performed, including variables from different levels. The modeling was initiated by a null model to verify random effects, and variables 
Table 1. Individual and contextual variables. General description and adaptation strategies of the analysis model. Brazil, 2013.

Variable Source Description Original categories
(new categories)

Dependent

Independent (Individual)

Socioeconomic Socioeconomic
stratification National Health Research

\section{Oral Health Self- $\quad$ National Health Research} Perception 2013 (PNS, 2013)

Gender

National Health Research

Race (skin color)

National Health Research Self-reported

Demographic

Age

National Health Research Age, in years, at the

\section{Literacy}

Lifestyle

Healthy eating habits

ational Health Research

Years of schooling expectancy at 18 years old Per capita income Brazilian Institute Statistics (IBGE, from the

Independent (Context)
Socioeconomic

National Census, performed by the Brazilian Institute

Gini Index

Human Development Index (HDI)

Oral Health Services
Oral Health Primary Care 2013 (PNS, 2013 2013 (PNS, 2013) Gender of interviewee. 2013 (PNS, 2013) kin color of interviewee. 2013 (PNS, 2013) moment of the interview.

National Health Research Answer to the question "Can 2013 (PNS, 2013) you read and write?"

The "Brazil Criterion of

Economic Classification"16 It is based on possession of goods, such as a car, microcomputer, refrigerator, $\mathrm{TV}$ washing machine, DVD player microwave, motorcycle and mobile phone. The presence of bathroom and housekeeper were also recorded, and the householder's educational status was also included. Each item has different weights. The variable represents the families' purchasing power. The variables consume salad, vegetables, fruit juice, soft drinks, and candies were included in

$\mathrm{N}$ 2013 (PNS, 2013 ) a factorial analysis, creating two new factors. The factor containing salad, vegetables, fruit juice was denomination "health eating habits".

National Census, performed by the

Brazilian Institute of Geography and Statistics (IBGE, from the

Portuguese acronym)

National Census, performed by the of Geography and Portuguese acronym) of Geography and Portuguese acronym)

Brazilian agency of the United Nations Development Program (UNDP)
Statistics (IBGE, from the

Very good (Good)

Good (Good)

Not good, not bad (Bad)

Bad (Bad)

Very bad (Bad)

Male and Female, no modification

White (white)

Black (non-white)

Asian (non-white)

Mixed color (non-white) Indian (non-white)

Years, from 18 to 99, categorized to:

18-24

25-40

41-59

60 and older

Yes or No, no modification

A numeric value, ranging from 0 to 46 . Classes were

defined as follows:

A1 - 42 to 46 (A or B)

$A 2-35$ to 41 ( $A$ or $B$ )

$\mathrm{B} 1-29$ to 34 (A or B)

$\mathrm{B} 2-23$ to 38 ( $\mathrm{A}$ or $\mathrm{B})$

C1 -18 to $22(\mathrm{C})$

C2 - 14 to 17 (C)

$\mathrm{D}-8$ to 13 (D or $\mathrm{E})$

$E-0$ to 7 (D or $E$ )

A numeric value, categorized from median as "Yes" or "No"

Average of years of schooling that a child should complete before 18 years old.

The sum of the income of all household members, divided by the number of residents.

An index to measure the inequality in the distribution of per capita income. Ranging from 0 , where there is no inequality, to 1 when all

income is concentrated in one single individual.

Geometric average of three other indices related to

education, income, and longevity, with equal weights.

National Health Facilities Number of oral health teams in

Register (CNES from the primary care services, divided by Portuguese acronym) the population in the same year.
Numeric value, categorized from the median in:

9.4 years and more Up to 9.4 years

Numeric value, categorized from the median in:

BR R\$671 or more Up to BR R $\$ 670$

Numeric value, categorized from the median in: Up to 0.600 0.601 and more

Numeric value, categorized from the median in: 0.709 and more Up to 0.708

Numeric value, categorized from the median in:

14.7 and more Up to 14.6 


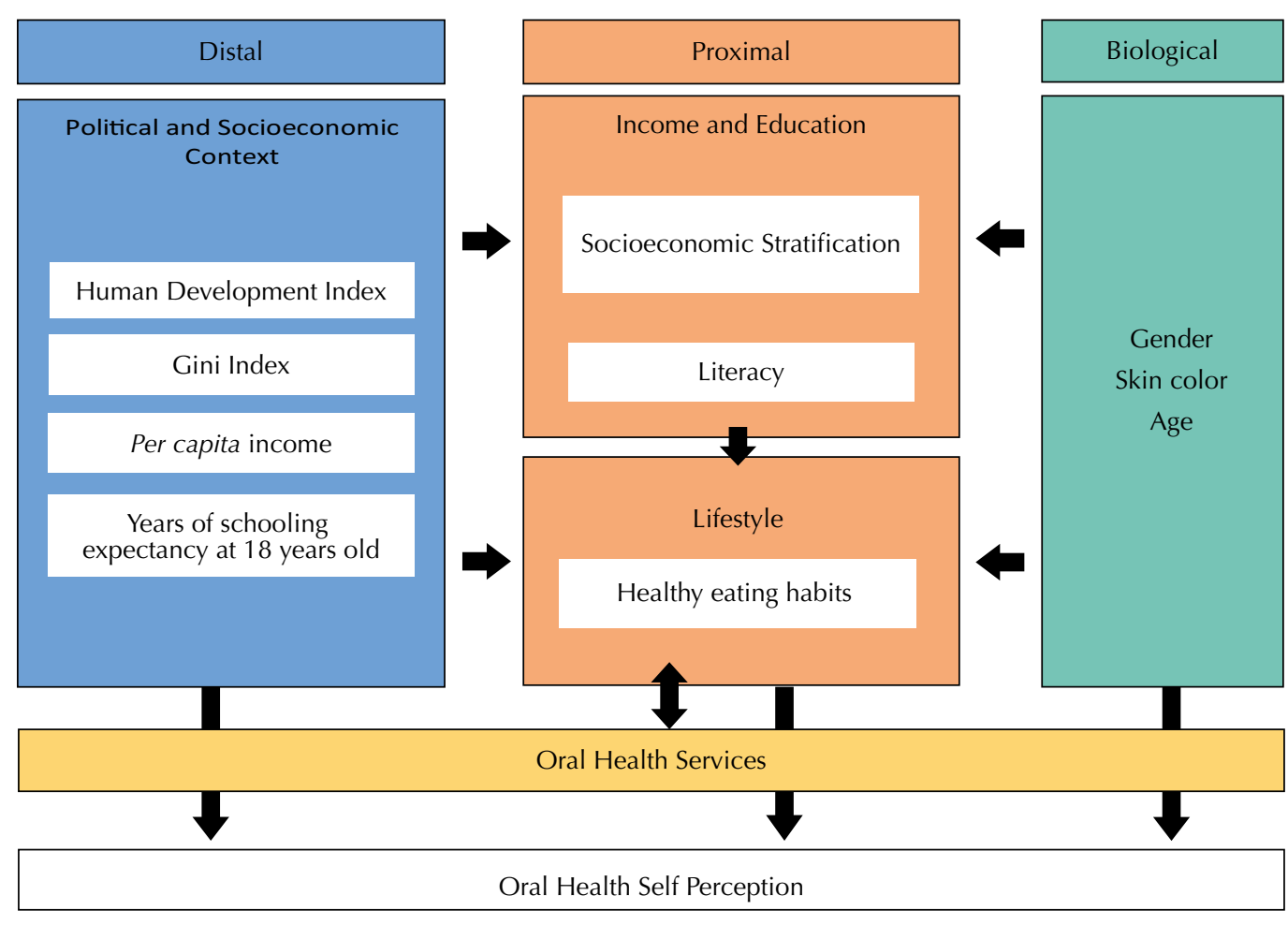

Figure. Framework of the study. Brazil, 2013.

from each dimension were included (demographic, socioeconomic, lifestyle etc.). The term of interaction between the socioeconomic contextual and individual variables was created to analyze the cross-level interaction.

\section{RESULTS}

Regarding the general characteristics of the sample, $52.9 \%$ were women, $52.5 \%$ self-reported as non-white, $66.0 \%$ were aged between 25 to 59 years, $91.5 \%$ were literate, $39.6 \%$ were "class C" according to the "Brazil criterion" and $52.7 \%$ were individuals with healthy eating habits. The years of schooling expectancy was 9.6 years and the average per capita income was $\mathrm{R} \$ 729.00$. Gini index presented an average of 0.577 , HDI was 0.711 . The population rate of oral health teams in primary care was 14.39 and 0.53 per 100,000 inhabitants. In general, $67.4 \%$ of interviewees related their oral health as being good or very good (Table 2).

Bivariate analysis at the individual level showed that women had better oral health than men ( $\mathrm{PR}=0.91,95 \% \mathrm{CI} 0.87-0.95)$ and the prevalence of bad oral health in non-white people was $40.0 \%$ higher than in white people $(\mathrm{PR}=1.40,95 \% \mathrm{CI} 1.34-1.47)$. There was an increase in the prevalence of bad oral health as age increased $(\mathrm{p}<0.001)$. The association with socioeconomic stratification and healthy eating habits also showed a dose-response effect. The worse the classification of the independent variable, the worse the prevalence of bad oral health.

A higher prevalence of bad oral health was associated to lower years of schooling expectancy ( $\mathrm{PR}=1.31,95 \% \mathrm{CI} 1.26-1.37)$, lower per capita income ( $\mathrm{PR}=1.45,95 \% \mathrm{CI} 1.39-1.52)$, higher income concentration ( $\mathrm{PR}=1.41,95 \% \mathrm{CI} 1.35-1.47)$, and worse human development $(\mathrm{PR}=1.45,95 \% \mathrm{CI} 1.39-1.52)$. Inversely, oral health primary care services were negatively associated with oral health perception. A higher prevalence of good oral health was present in places with lower coverage for these services (Table 3).

Concerning multilevel modeling, the initial null model indicated that there is compelling evidence that the between-community (in our case, states) variance is non-zero, as the Likelihood Ratio (LR) test statistic is 502.05 with a corresponding $p$-value $\leq 0.001$ (Table 4). 
Table 2. Descriptive analysis of the variables according to the levels. Brazil, 2013.

\begin{tabular}{|c|c|c|}
\hline Variable & $\%$ & $95 \% \mathrm{Cl}$ \\
\hline \multicolumn{3}{|c|}{ 1st level (individual) } \\
\hline \multicolumn{3}{|c|}{ Oral Health Self-Perception } \\
\hline Good or very good & 67.4 & $66.7-68.1$ \\
\hline Regular to very bad & 32.6 & 31.9-33.3 \\
\hline \multicolumn{3}{|l|}{ Sex } \\
\hline Male & 47.1 & $46.4-47.9$ \\
\hline Female & 52.9 & $52.1-53.6$ \\
\hline \multicolumn{3}{|l|}{ Skin color } \\
\hline White & 47.5 & $46.7-48.3$ \\
\hline Black or Mixed & 52.5 & $51.7-53.3$ \\
\hline \multicolumn{3}{|l|}{ Age (years) } \\
\hline 18 to 24 & 15.9 & $15.4-16.5$ \\
\hline 25 to 40 & 33.6 & $32.9-34.3$ \\
\hline 41 to 59 & 32.4 & $31.7-33.1$ \\
\hline 60 and older & 18.0 & $17.5-18.7$ \\
\hline \multicolumn{3}{|l|}{ Literate } \\
\hline Yes & 91.5 & $91.1-91.9$ \\
\hline No & 8.5 & $8.1-8.9$ \\
\hline \multicolumn{3}{|c|}{ Socioeconomic stratification } \\
\hline$A$ or $B$ & 25.9 & $25.3-26.9$ \\
\hline $\mathrm{C}$ & 39.6 & $38.9-40.2$ \\
\hline $\mathrm{D}$ or $\mathrm{E}$ & 34.5 & $34.0-35.1$ \\
\hline \multicolumn{3}{|l|}{ Healthy eating habits } \\
\hline Yes & 52.7 & $51.9-53.6$ \\
\hline No & 47.3 & $46.4-48.1$ \\
\hline \multicolumn{3}{|c|}{ 2nd level (state) } \\
\hline \multicolumn{3}{|c|}{ Years of schooling expectancy at 18 years old } \\
\hline 9.4 and more & 60.7 & $60.1-61.2$ \\
\hline Up to 9.4 & 39.3 & $38.8-39.9$ \\
\hline \multicolumn{3}{|c|}{ Per capita income (BR R\$) } \\
\hline 671 and more & 65.9 & $65.4-66.5$ \\
\hline Up to 670 & 34.1 & $33.5-34.6$ \\
\hline \multicolumn{3}{|l|}{ Gini Index } \\
\hline Up to 0.600 & 68.0 & $67.4-68.5$ \\
\hline 0.601 and more & 32.0 & $31.5-32.6$ \\
\hline \multicolumn{3}{|c|}{ Human Development Index (HDI) } \\
\hline 0.709 and more & 65.9 & $65.4-66.5$ \\
\hline Up to 0.708 & 34.1 & $33.5-34.6$ \\
\hline \multicolumn{3}{|c|}{ Oral Health Primary Care } \\
\hline 14.7 and more & 49.5 & $48.9-50.1$ \\
\hline Up to 14.6 & 50.5 & $49.9-51.1$ \\
\hline
\end{tabular}

In model 1, when only the individual variables were included, all of them remained significant. The PR values and their respective confidence intervals were slightly adjusted in relation to bivariate analysis. When the contextual variables were included, a collinear effect between per capita income and HDI was observed, so the first one was not included in the next model. In the final model, variables that lost statistical significance were excluded; however, we included the last block with variable related to oral health services. The final model consisted of all individual variables except "literacy" and the contextual variables "HDI" and "oral health primary care", which remained significant. All estimates were adjusted at the final 
Table 3. Bivariate associations between outcome and the independent variables according to the levels. Brazil, 2013.

\begin{tabular}{|c|c|c|c|c|c|c|}
\hline \multirow{3}{*}{ Variable } & \multicolumn{4}{|c|}{ Oral Health Self-Perception } & \multirow{3}{*}{$\mathbf{p}$} & \multirow{3}{*}{ PR $(95 \% \mathrm{Cl})$} \\
\hline & \multicolumn{2}{|c|}{ Good/Very good } & \multicolumn{2}{|c|}{ Regular to very bad } & & \\
\hline & $\%$ & $95 \% \mathrm{Cl}$ & $\%$ & $95 \% \mathrm{Cl}$ & & \\
\hline \multicolumn{7}{|c|}{ 1st level (individual) } \\
\hline \multicolumn{7}{|l|}{ Sex } \\
\hline Male & 65.8 & $64.7-66.8$ & 34.2 & $33.2-35.3$ & $<0.001$ & 1 \\
\hline Female & 68.9 & $68.0-69.8$ & 31.1 & $30.2-31.9$ & & $0.91(0.87-0.95)$ \\
\hline \multicolumn{7}{|l|}{ Skin color } \\
\hline White & 73.1 & $72.2-74.1$ & 26.9 & $25.9-27.8$ & $<0.001$ & 1 \\
\hline Black or Mixed & 62.3 & $61.3-63.3$ & 37.7 & $36.7-38.7$ & & $1.40(1.34-1.47)$ \\
\hline \multicolumn{7}{|l|}{ Age (years) } \\
\hline 18 to 24 & 74.5 & $72.7-76.1$ & 25.5 & $23.9-27.9$ & $<0.001$ & 1 \\
\hline 25 to 40 & 70.8 & $69.7-71.9$ & 29.2 & $28.1-30.3$ & & $1.14(1.06-1.24)$ \\
\hline 41 to 59 & 63.3 & $62.0-64.6$ & 36.7 & $35.4-38.0$ & & $1.44(1.34-1.55)$ \\
\hline 60 years and older & 62.3 & $60.6-63.9$ & 37.7 & $36.1-39.4$ & & $1.48(1.36-1.60)$ \\
\hline \multicolumn{7}{|l|}{ Literate } \\
\hline Yes & 68.9 & $68.2-69.6$ & 31.1 & $30.4-31.8$ & $<0.001$ & 1 \\
\hline No & 51.6 & $49.2-54.1$ & 48.4 & $45.9-50.8$ & & $1.55(1.47-1.64)$ \\
\hline \multicolumn{7}{|c|}{ Socioeconomic stratification } \\
\hline$A$ or $B$ & 74.9 & $73.5-76.3$ & 25.1 & $23.7-26.5$ & $<0.001$ & 1 \\
\hline $\mathrm{C}$ & 67.4 & $66.4-68.5$ & 32.6 & $31.5-33.6$ & & $1.30(1.22-1.38)$ \\
\hline $\mathrm{D}$ or $\mathrm{E}$ & 61.8 & $60.7-62.8$ & 38.2 & $37.2-39.3$ & & $1.53(1.44-1.62)$ \\
\hline \multicolumn{7}{|l|}{ Healthy eating habits } \\
\hline Yes & 72.5 & $71.5-73.4$ & 27.5 & $26.6-28.5$ & $<0.001$ & 1 \\
\hline No & 61.8 & $60.8-62.8$ & 38.2 & $37.2-39.2$ & & $1.39(1.33-1.45)$ \\
\hline \multicolumn{7}{|c|}{ 2nd level (state) } \\
\hline \multicolumn{7}{|c|}{ Years of Schooling Expectancy at 18 years old } \\
\hline 9.4 and more & 71.0 & $70.0-72.0$ & 29.0 & $28.0-30.0$ & $<0.001$ & 1 \\
\hline Up to 9.4 & 61.9 & $60.9-62.9$ & 38.1 & $37.1-39.1$ & & $1.31(1.26-1.37)$ \\
\hline \multicolumn{7}{|c|}{ Per capita income (BR R\$) } \\
\hline 671 and more & 71.8 & $70.8-72.7$ & 28.2 & $27.3-29.2$ & $<0.001$ & 1 \\
\hline Up to 670 & 59.0 & $58.0-60.0$ & 41.0 & $40.0-42.0$ & & $1.45(1.39-1.52)$ \\
\hline \multicolumn{7}{|l|}{ Gini Index } \\
\hline Up to 0.600 & 71.2 & $70.2-72.1$ & 28.8 & $27.9-29.8$ & $<0.001$ & 1 \\
\hline 0.601 and more & 59.5 & $58.4-60.5$ & 40.5 & $39.5-41.6$ & & $1.41(1.35-1.47)$ \\
\hline \multicolumn{7}{|c|}{ Human Development Index (HDI) } \\
\hline 0.709 and more & 71.8 & $70.8-72.7$ & 28.2 & $27.3-29.2$ & $<0.001$ & 1 \\
\hline Up to 0.708 & 59.0 & $58.0-60.0$ & 41.0 & $40.0-42.0$ & & $1.45(1.39-1.52)$ \\
\hline \multicolumn{7}{|c|}{ Oral Health Primary Care } \\
\hline 14.7 and more & 63.8 & $62.8-64.9$ & 36.2 & $35.1-37.2$ & $<0.001$ & 1 \\
\hline Up to 14.6 & 71.0 & $69.9-72.0$ & 29.0 & $28.0-30.1$ & & $0.80(0.77-0.84)$ \\
\hline
\end{tabular}

model and the LR test showed that the contextual effect maintained its significance. A better adjustment was verified for HDI and socioeconomic stratification (especially “D or E” class).

There was a steady decline in the values of variance from the null model to the final, starting with $62.0 \%$ from null model to the first and ending with an overall reduction of $90.0 \%$, showing a strong effect of the context, considering the state federative units in Brazil. The inclusion of the interaction term, created from socioeconomic stratification and HDI, did not cause a significant modification in the variance in the adjusted final model. To confirm 
Table 4. Poisson multilevel regression analysis for bad oral health self-perception according to individual and contextual variables. Brazil, 2013.

\begin{tabular}{|c|c|c|c|c|c|c|c|}
\hline \multirow{2}{*}{ Variable } & \multirow{2}{*}{$\begin{array}{l}\text { Null Model } \\
(n=60,202)\end{array}$} & \multicolumn{2}{|c|}{ Model $1(n=60,199)$} & \multicolumn{2}{|c|}{ Model $2(n=60,199)$} & \multicolumn{2}{|c|}{ Final Model $(n=60,199)$} \\
\hline & & PR $(95 \% C l)$ & $\mathbf{p}$ & PR $(95 \% \mathrm{CI})$ & p & PR $(95 \% C I)$ & p \\
\hline \multicolumn{8}{|c|}{ 1st Level (individual) } \\
\hline \multicolumn{8}{|l|}{ Sex } \\
\hline Male & & 1 & & 1 & & 1 & \\
\hline Female & & $0.94(0.92-0.97)$ & $<0.001$ & $0.94(0.92-0.97)$ & $<0.001$ & $0.94(0.91-0.97)$ & $<0.001$ \\
\hline \multicolumn{8}{|l|}{ Skin color } \\
\hline White & & 1 & & 1 & & 1 & \\
\hline Black or Mixed & & $1.19(1.15-1.23)$ & $<0.001$ & $1.18(1.15-1.22)$ & $<0.001$ & $1.19(1.16-1.23)$ & $<0.001$ \\
\hline \multicolumn{8}{|l|}{ Age (years) } \\
\hline 18 to 24 & & 1 & & 1 & & 1 & \\
\hline 25 to 40 & & $1.16(1.10-1.22)$ & $<0.001$ & $1.16(1.10-1.22)$ & $<0.001$ & $1.17(1.11-1.22)$ & $<0.001$ \\
\hline 41 to 59 & & $1.44(1.37-1.51)$ & $<0.001$ & $1.44(1.37-1.51)$ & $<0.001$ & $1.47(1.40-1.54)$ & $<0.001$ \\
\hline 60 and older & & $1.49(1.42-1.58)$ & $<0.001$ & $1.50(1.42-1.58)$ & $<0.001$ & $1.57(1.49-1.65)$ & $<0.001$ \\
\hline \multicolumn{8}{|l|}{ Literate } \\
\hline Yes & & 1 & & 1 & & - & \\
\hline No & & $1.17(1.12-1.22)$ & $<0.001$ & $1.17(1.12-1.22)$ & $<0.001$ & - & \\
\hline \multicolumn{8}{|c|}{ Socioeconomic stratification } \\
\hline A or B & & 1 & & 1 & & 1 & \\
\hline $\mathrm{C}$ & & $1.18(1.13-1.23)$ & $<0.001$ & $1.17(1.13-1.22)$ & $<0.001$ & $1.18(1.13-1.23)$ & $<0.001$ \\
\hline $\mathrm{D}$ or $\mathrm{E}$ & & $1.24(1.19-1.29)$ & $<0.001$ & $1.24(1.17-1.29)$ & $<0.001$ & $1.27(1.21-1.31)$ & $<0.001$ \\
\hline \multicolumn{8}{|c|}{ Healthy eating habits } \\
\hline Yes & & 1 & & 1 & & 1 & \\
\hline No & & $1.32(1.28-1.36)$ & $<0.001$ & $1.31(1.27-1.35)$ & $<0.001$ & $1.33(1.29-1.37)$ & $<0.001$ \\
\hline \multicolumn{8}{|c|}{ 2nd level (state) } \\
\hline
\end{tabular}

Years of Schooling Expectancy at 18 years old

9.4 and more

Up to 9.4

Gini Index

Up to 0.600

0.601 and more

Human Development Index (HDI)

0.709 and more

Up to 0.708

Oral Health Primary Care

14.7 and more

Up to 14.6

Fixed Effects

Intercept (95\%IC)

$-1.06(-1.13--0.99) \quad 0.18(0.17-0.19)$

0.011

(0.016-0.050) (0.006-0.021)

$502.05(<0.001) \quad 143.03(<0.001)$
1

$1.02(0.95-1.10)$

0.503

\section{1}

$1.02(0.94-1.10)$

0.659

$1.16(1.07-1.26)<0.001$

$1.19(1.12-1.26)$

$<0.001$

$0.93(0.88-0.98)$

0.009

$0.16(0.15-0.17)$

$0.16(0.15-0.18)$

0.004

(0.002-0.008)

0.003

(0.002-0.007)

$30.07(<0.001)$

$18.08(<0.001)$

LR: Likelihood Ratio

this assumption, we also performed stratified analyses, observing the values of RP for the association between oral health perception and socioeconomic stratification for each category of HDI. There were no differences in these values, therefore, these results indicate that there are no cross-level interactions. 


\section{DISCUSSION}

Both individual factors and characteristics of the context where people live were synergistically associated in their perception of oral health, as has been found in other studies ${ }^{11,14,20}$. This study has proposed a multilevel analysis to assess the social determinants of self-reported oral health status, understanding that only individual factors cannot be sufficient to explain how oral health status is perceived by people. Our perspective is that an individual is embedded in a collective context with social, economic, and political characteristics, which profoundly differ regardless of the scale of territory, as inequalities can be expressed in countries, states, cities and even neighborhoods.

Human Development Index, as a measure of the quality of life, maintained a significant effect, thus showing that better oral health is present in individuals living in places with higher HDI. This fact shows us the importance of investment in social public policies to enhance the population's quality of life, and hence their oral health perception ${ }^{21}$. Other contextual variables, such as Gini index, lost their significance after adjustment, very likely due to its small variation among the Brazilian federative units. According to Barros et al. ${ }^{22}$, despite showing better indicators in the South and Southeast regions, income inequality is still uniform throughout the whole country, probably because inequality is affected more by national economic policies and less by state-level interventions. Wilkinson and Pickett ${ }^{23}$ pointed out that the association between income inequality and health are more likely to be found in studies performed with large areas, usually international studies that use countries as a unit of analyses. In studies where the analyses were done in states, cities or regions, even in small units, such as counties, neighborhoods or census tracks, the results are usually inconclusive.

The results for oral health services in primary care have shown that places with higher coverage for these services also have a higher prevalence of bad self-perceived oral health. Although this could be counterintuitive, it can be interpreted that there has been a more equitable distribution of public resources because a major amount of them have been deployed to the neediest places. Working with cross-sectional data (as we did), it is impossible to assess whether public health services would have a mitigating effect on the inequalities in oral health; such an effect could only be assessed through longitudinal studies. However, our results are in accordance with the current principles of the Brazilian National Oral Health Policy in Brazil (PNSB), which states that the distribution of resources must be based on equity ${ }^{24}$.

Nevertheless, in analyzing the implementation of the PNSB, it is possible to notice after more than a decade that the most vulnerable social regions where these health services have been deployed are still showing worse indicators. This means that, actually, there was no significant change in the oral health assistance model ${ }^{25-27}$.

Secondary oral health services have lost their significance in the adjusted model. According to Soares ${ }^{28}$, despite the quantitative expansion of oral health specialized services in the last decade in Brazil, difficulties in accessing these services persist in many regions. Moreover, Góes et al. ${ }^{29}$ found that the low coverage of oral health in primary care alongside its inadequate structure are both important factors that compromise comprehensive specialized oral health care.

Regarding the determinants of the work and life conditions, several studies have shown that educational status is an important factor in the oral health determination ${ }^{1,5,11,20,22,30}$, which was not found in our study. This is probably because the variable "literacy" has poor discriminant power, as can be confirmed by the high number of literate people in the whole sample. On the other hand, socioeconomic stratification also showed a dose-response effect, even after adjustment, i.e., the lower the socioeconomic status, the worse the oral health condition. Similar findings were observed by other authors ${ }^{1,5,14,20}$. Regarding household crowding, this variable reflects the family economic situation, as the more people living in small houses, the less the family income. Thus, economically privileged families (as measured in this study) essentially represent the families' purchasing power, so it is expected that these family members have more access to health services, more information about oral health prevention, and consequently, have better oral health. 
Individual behaviors, personal choices, and lifestyle also showed an important role in oral health perception determination, as was also found by Gabardo et al..$^{14}$ In our study, people with healthy eating habits and those that related using dental floss presented better oral health, even after the adjustment for all other variables, which also has strong scientific evidence ${ }^{14,31}$. Although choosing a healthy lifestyle could be considered as an individual decision, it is also socially influenced through economic and cultural issues alongside access to health services; therefore, it is considered a social determinant ${ }^{21}$.

We found better oral health in women compared to men, which disagrees with the results of some authors ${ }^{1,14}$. However, our findings could be explained by the fact that women usually have more focused attitudes on oral health care compared to $\operatorname{men}^{1}$ and hence express better oral health perception ${ }^{32}$. In relation to age, we observe a dose-response effect, even after adjustment, i.e., the higher the age the worse is the oral health condition. Dental caries and periodontal diseases usually have a cumulative effect, so older people have a life trajectory of suffering because of these diseases, and thus report bad oral health more often. Similar findings were found by several authors ${ }^{1,14,20}$. In relation to skin color, worse oral health was referred by non-white people, in accordance with Barbosa et al. ${ }^{33}$ Such an outcome was expected, as in most studies in Brazil, race (or ethnicity, skin color) can be considered as a proxy of socioeconomic status ${ }^{34,35}$, but it is noteworthy that race maintained its significance even in the presence of other variables such as socioeconomic stratification. This could indicate that skin color is in itself an important marker in oral health inequalities ${ }^{36}$.

Some studies using multilevel techniques have found a strong relationship between social disparities and health inequalities ${ }^{25,37-39}$. Multilevel modeling has been adopted in several studies as a powerful instrument to elucidate the influence of both individual and contextual factors on health population. Nevertheless, it is also important to understand the subjectivity involved in oral illness and how these interlaced characteristics could reflect on oral health perception, which is affected by indicators beyond those related to clinical conditions. In order to promote better oral health to the population, it is crucial to include measures that tackle both the main individual factors and those related to quality of life and egalitarian social policies.

In this study, the aggregation unit used was the Brazilian federation unit, due to the availability of representative data in this level of aggregation. However, this unit of aggregation is not ideal because, within it, there is still a lot of context variability. Our explanatory theoretical model is still reductionist in face of the complexity of factors that affect the social context regarding individuals and their perception. However, such limitations do not invalidate the findings here. Further studies may complement these findings and deepen the discussion here.

The bad oral health perception is determined by a combination of biological, proximal, and distal factors, as discussed in our framework. These gradients of oral health related to these factors can be considered unfair and avoidable, which allude to social inequalities.

\section{REFERENCES}

1. Mendonça HLC, Szwarcwald CL, Damacena GN. [Self-rated oral health: results of the World Health Survey - Primary Care in four municipalities in Rio de Janeiro State, Brazil, 2005]. Cad Saude Publica. 2012;28(10):1927-38. Portuguese. https://doi.org/10.1590/S0102-311X2012001000011

2. Malta DC, Leal MC, Costa MFL, Morais Neto OL. Inquéritos Nacionais de Saúde: experiência acumulada e proposta para o inquérito de saúde brasileiro. Rev Bras Epidemiol. 2008;11 Supl 1:159-67. https://doi.org/10.1590/S1415-790X2008000500017

3. Bellon ML, Ambrosano GMB, Pereira SM, Sales-Peres SHC, Meneghim MC, Pereira AC, et al. [Sample size and costs estimate in epidemiological survey of dental caries]. Rev Bras Epidemiol. 2012;15(1):96-105. Portuguese. https://doi.org/10.1590/S1415-790X2012000100009

4. Szwarcwald CL, Malta DC, Pereira CA, Vieira MLFP, Conde WL, Souza-Júnior PRB, et al. [National Health Survey in Brazil: design and methodology of application]. Cienc Saude Coletiva. 2014;19(2):333-42. Portuguese. https://doi.org/10.1590/1413-81232014192.14072012 
5. Mansyur C, Amick BC, Harrist RB, Franzini L. Social capital, income inequality, and self-rated health in 45 countries. Soc Sci Med. 2008;66(1):43-56. https://doi.org/10.1016/j.socscimed.2007.08.015

6. Luchi CA, Peres KG, Bastos JL, Peres MA. Inequalities in self-rated oral health in adults. Rev Saude Publica. 2013;47(4):740-51. https://doi.org/10.1590/S0034-8910.2013047004364

7. Nogueira RP, organizador. Determinação social da saúde e reforma sanitária. Rio de Janeiro: Cebes; 2010 [cited 2016 Apr 13]. (Coleção Pensar em Saúde). Available from: http://cebes.org. br/site/wp-content/uploads/2011/01/Determinacao.pdf

8. Freire MCM, Martins AB, Santos CR, Martins NO, Filizzola EM, Jordão LMR, et al. Oral health status, behaviours, self-perception and associated impacts among university students living in student residences. Rev Odontol UNESP. 2012;41(3):185-91.

9. Gabardo MCL, Moysés ST, Moysés S. Autopercepção de saúde bucal conforme o Perfil de Impacto da Saúde Bucal (OHIP) e fatores associados: revisão sistemática. Rev Panam Salud Publica. 2013 [cited 2016 Apr 13];33(6):439-45. Available from: http://www.scielosp.org/pdf/rpsp/v33n6/09.pdf

10. Fadel CB, Valentim LM, Fillus TM, Langoski JE, Bordin D. Oral health, the perspective of the inmate and the context of vulnerability. Rev Odontol UNESP. 2015;44(6):368-73. https://doi.org/10.1590/1807-2577.05615

11. Tassinari WS, León AP, Werneck GL, Faerstein E, Lopes CS, Chor D, et al. [Socioeconomic context and perceived oral health in an adult population in Rio de Janeiro, Brazil: a multilevel analysis]. Cad Saude Publica. 2007;23(1):127-36. Portuguese. https://doi.org/10.1590/S0102-311X2007000100014

12. Turrell G, Sanders AE, Slade GD, Spencer AJ, Marcenes W. The independent contribution of neighborhood disadvantage and individual-level socioeconomic position to self-reported oral health: a multilevel analysis. Community Dent Oral Epidemiol. 2007;35(3):195-206. https://doi.org/10.1111/j.1600-0528.2006.00311.x

13. Cremonese C, Backes V, Olinto MTA, Dias-da-Costa JS, Pattussi MP. Neighborhood sociodemographic and environmental contexts and self-rated health among Brazilian adults: a multilevel study. Cad Saude Publica. 2010;26(12):2368-78. https://doi.org/10.1590/S0102-311X2010001200015

14. Gabardo MCL, Moysés SJ, Moysés ST, Olandosky M, Olinto MTA, Pattussi MP. Multilevel analysis of self-perception in oral health and associated factors in Southern Brazilian adults: a cross-sectional study. Cad Saude Publica. 2015;31(1):49-59. https://doi.org/10.1590/0102-311X00037814

15. Comissão Nacional sobre Determinantes Sociais da Saúde. As causas sociais das iniquidades em saúde no Brasil. Rio de Janeiro: Fiocruz; 2008 [cited 2016 Apr 13]. Available from: http://bvsms. saude.gov.br/bvs/publicacoes/causas_sociais_iniquidades.pdf

16. Damacena GN, Szwarcwald CL, Souza-Júnior PRB, Vieira MLFP, Pereira CA, Morais Neto OL, et al. The development of the National Health Survey in Brazil, 2013. Epidemiol Serv Saude. 2015;24(2):197-206. https://doi.org/10.1590/S0102-311X2007000100014

17. Puente-Palacios KE, Laros JA. [Multilevel analysis: contributions to studies investigating the effects of social context on individual behavior]. Estud Psicol (Campinas). 2009;26(3):349-61. Portuguese. https://doi.org/10.1590/S0103-166X2009000300008

18. Associação Brasileira de Empresas de Pesquisa. Critério de Classificação Econômica Brasil 2015. São Paulo: ABEP; 2014 [cited 2016 Apr 13]. Available from: http://www.abep.org/criterio-brasil

19. Hair JF Jr, Black WC, Babin BJ, Anderson RE, Tatham RL. Análise multivariada de dados. 6.ed. Porto Alegre: Bookman; 2009.

20. Cohen-Carneiro F, Souza-Santos R, Rebelo MAB. Quality of life related to oral health: contribution from social factors. Cienc Saude Coletiva. 2011;16 Supl 1:1007-15. https://doi.org/10.1590/S1413-81232011000700033

21. Guerra MJ, Greco RM, Leite IC, Ferreira EF, MVQ. Impact of oral health conditions on the quality of life of workers. Cienc Saude Coletiva. 2014;19(12):4777-86. https://doi.org/10.1590/S1413-81232011000700033

22. Barros RP, Foguel MN, Ulyssea G, organizadores. Desigualdade de renda no Brasil: uma análise da queda recente. Vol 2. Brasília (DF): Ipea; 2007.

23. Wilkinson RG, Pickett KE: Income inequality and population health: a review and explanation of the evidence. Soc Sci Med. 2006;62(7):1768-84. https://doi.org/10.1016/j.socscimed.2005.08.036

24. Ministério da Saúde (BR), Secretaria de Atenção à Saúde, Departamento de Atenção Básica, Coordenação Nacional de Saúde Bucal. Diretrizes da Política Nacional de Saúde Bucal. Brasília (DF); 2004 [cited 2016 Apr 13]. Available from: http://189.28.128.100/dab/docs/publicacoes/ geral/diretrizes_da_politica_nacional_de_saude_bucal.pdf 
25. Roncalli AG, Tsakos G, Sheiham A, Souza GC, Watt RG. Social determinants of dental treatment needs in Brazilian adults. BMC Public Health. 2014;14:1097. https://doi.org/10.1186/1471-2458-14-1097

26. Aquilante AG, Aciole GG. Building a "Smiling Brazil"? Implementation of the Brazilian National Oral Health Policy in a health region in the State of São Paulo. Cad Saude Publica. 2015;31(1):82-96. https://doi.org/10.1590/0102-311X00193313

27. Moysés SJ. Oral health programming and its relationship to epidemiology: challenges and opportunities. Cad Saude Publica. 2014;30(6):1136-8. https://doi.org/10.1590/0102-311XPE010614

28. Soares CLM. Constructing public oral health policies in Brazil: issues for reflection. Braz Oral Res. 2012;26 Spec No 1:94-102. https://doi.org/10.1590/S1806-83242012000700014

29. Goes PSA, Figueiredo N, Neves JC, Silveira FMM, Costa JFR, Pucca Júnior A, et al. [Evaluation of secondary care in oral health: a study of specialty clinics in Brazil]. Cad Saude Publica. 2012;28 Supl: s81-9. Portuguese. https://doi.org/10.1590/S0102-311X2012001300009

30. Peres MA, Iser BPM, Boing AF, Yokota RTC, Malta DC, Peres KG. [Inequalities in access to and utilization of dental care in Brazil: an analysis of the Telephone Survey Surveillance System for Risk and Protective Factors for Chronic Diseases (VIGITEL 2009)]. Cad Saude Publica. 2012;28 Supl: s90-100. Portuguese. https://doi.org/10.1590/S0102-311X2012001300010

31. Rodrigues LC. [Perception of health of adolescent that received dental care in the first decade of life] [dissertation]. Araçatuba: Universidade Estadual Paulista, Faculdade de Odontologia de Araçatuba; 2016. Portuguese

32. Hernández-Palacios RD, Ramírez-Amador V, Jarillo-Soto EC, Irigoyen-Camacho ME, Mendoza-Núñez VM. Relationship between gender, income and education and selfperceived oral health among elderly Mexicans: an exploratory study. Cienc Saude Coletiva. 2015;20(4):997-1004. https://doi.org/10.1590/1413-81232015204.00702014

33. Barbosa TB, Junqueira SR, Frias AC, Araujo ME. [Perception of Brazilian adolescents about the influence of oral health on biological and social functions]. Pesq Bras Odontoped Clin Integr. 2013;13(2):171-6. Portuguese. https://doi.org/10.4034/pboci.v13i2.1531

34. Marin-Leon L, Francisco PMSB, Segall-Corrêa AM, Panigassi G. Household appliances and food insecurity: gender, referred skin color and socioeconomic differences. Rev Bras Epidemiol. 2011;14(3):398-410. https://doi.org/10.1590/S1415-790X2011000300005

35. Kabad JF, Bastos JL, Santos RV. [Race, color and ethnicity in epidemiologic studies carried out with Brazilian populations: systematic review on the PubMed database]. Physis. 2012;22(3):895-918. Portuguese. https://doi.org/10.1590/S0103-73312012000300004

36. Bastos JL, Antunes JLF, Frias AC, Souza MLR, Peres KG,Peres MA. Color/race inequalities in oral health among Brazilian adolescents. Rev Bras Epidemiol. 2009;12(3):313-24. https://doi.org/10.1590/S1415-790X2009000300003

37. Chauvel L, Leist AK. Socioeconomic hierarchy and health gradient in Europe: the role of income inequality and of social origins. Int J Equity in Health. 2015;14:132. https://doi.org/10.1186/s12939-015-0263-y

38. Adedini SA, Odimegwu C, Imasiku EN, Ononokpono DN, Ibisomi L. Regional variations in infant and child mortality in Nigeria: a multilevel analysis. J Biosoc Sci. 2015;47(2):165-87. https://doi.org/10.1017/S0021932013000734

39. Rathmann K, Ottova V, Hurrelmann K, Looze M, Levin K, Molcho M, et al. Macro-level determinants of young people's subjective health and health inequalities: a multilevel analysis in 27 welfare states. Maturitas. 2015;80(4):414-20. https://doi.org/10.1016/j.maturitas.2015.01.008

Author's Contribution: JVS and AGRCO participated in all research: conception, analysis, and interpretation of results and critical review of the content. All authors participated in the writing, approved the final version of the manuscript, and declare to be responsible for all aspects of the study.

Conflict of Interest: The authors declare no conflict of interest. 